\title{
Les sarcophages en grès de la bordure septentrionale du Massif Central
}

Production, diffusion, utilisations et remplois. Bilan de la première année du Projet collectif de recherche

Sophie Liégard, Alain Fourvel, Stéphane Büttner et Fabrice Henrion

\section{(2) OpenEdition}

Journals

Édition électronique

URL : https://journals.openedition.org/cem/725

DOI : $10.4000 /$ cem. 725

ISSN : 1954-3093

Éditeur

Centre d'études médiévales Saint-Germain d'Auxerre

Édition imprimée

Date de publication : 15 août 2005

ISSN : $1623-5770$

Référence électronique

Sophie Liégard, Alain Fourvel, Stéphane Büttner et Fabrice Henrion, « Les sarcophages en grès de la bordure septentrionale du Massif Central », Bulletin du centre d'études médiévales d'Auxerre | BUCEMA [En ligne], 9| 2005, mis en ligne le 29 novembre 2006, consulté le 22 septembre 2022. URL : http:// journals.openedition.org/cem/725; DOI : https://doi.org/10.4000/cem.725

Ce document a été généré automatiquement le 22 septembre 2022.

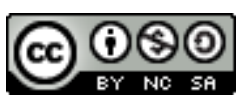

Creative Commons - Attribution - Pas d'Utilisation Commerciale - Partage dans les Mêmes Conditions 4.0 International - CC BY-NC-SA 4.0

https://creativecommons.org/licenses/by-nc-sa/4.0/ 


\section{Les sarcophages en grès de la bordure septentrionale du Massif Central}

Production, diffusion, utilisations et remplois. Bilan de la première année du Projet collectif de recherche

\section{Sophie Liégard, Alain Fourvel, Stéphane Büttner et Fabrice Henrion}

1 Ce PCR a été engagé en 2004, suite à une table ronde organisée à Clermont-Ferrand en 2003. Le constat avait été fait alors, que la connaissance effective de cette production de sarcophages en grès souffrait d'un manque d'études récentes.

2 Dans d'autres régions, ce sont, dans un premier temps, les décors des sarcophages, lorsque ceux-ci en étaient pourvus, qui ont fait l'objet de l'attention des chercheurs (Fossard 1953, Favière 1955, Berland 1965). Par la suite, les études ont été également axées sur les caractères techniques de ces objets comme ce fut le cas, entre autres, en Bourgogne (Büttner, Henrion 2001), en Lorraine (Cuvelier, Guillaume 1988) ou en Languedoc (Nécropoles 1987). Ce type d'approche, tentée aujourd'hui sur les sarcophages en grès, a comme objectif d'étudier les procédures de fabrication d'un point de vue technologique et morphologique, de caractériser les zones de production, de délimiter les zones de diffusion tout en ayant une réflexion sur les modes de transport. La prise en compte des objets en contexte archéologique peut également nous permettre d'envisager une typochronologie à l'instar de ce qui a pu être réalisé en Bourgogne du nord (Henrion 2000).

3 Les sarcophages en grès découverts dans le nord de l'Auvergne sont nombreux. Les actes des XIII ${ }^{\mathrm{e}}$ journées internationales d'archéologie mérovingienne, qui se sont tenues à Clermont-Ferrand en 1991 (Fizellier-Sauget 1999), s'en font d'ailleurs l'écho à travers les monographies des sites pour lesquels la présence de sarcophages en grès est avérée (Saint-Germain-des-Fossés, Creuzier-le-Vieux, Néris-les-Bains...). Depuis, quelques découvertes isolées ont été faites, mais à l'heure actuelle, seul le sarcophage mis au jour dans l'abbatiale Saint-Pierre de Souvigny a donné lieu à une véritable étude technique (Henrion à paraître). 
4 À partir des années 1970, les sarcophages en grès de ce secteur géographique ont été considérés comme appartenant au groupe nivernais en raison de la relative importance des découvertes dans cette région. Mais une origine bourbonnaise de la plupart de ces sarcophages a été démontrée et admise, notamment grâce aux analyses pétrographiques. Des découvertes ont confirmé que le Bourbonnais recelait bien des carrières de grès permien exploitées anciennement et que les sarcophages mis au jour dans les nécropoles locales étaient exclusivement en grès. Paradoxalement, aucune synthèse n'a jusqu'à ce jour porté sur ces éléments funéraires pourtant très répandus dans le centre de la France et dans les régions plus septentrionales.

5 Si les investigations dans les carrières de l'Allier démontrent clairement l'existence de production de sarcophages, en particulier à Coulandon et à Saint-Aubin-le-Monial (Liégard, Fourvel à paraitre) où des témoins d'extraction et de taille ont pu être mis en évidence, il apparait également qu'un autre centre de production, dans l'Autunois cette fois, fonctionne et diffuse également des sarcophages en grès. Quelques exemplaires taillés effectivement dans les grès du Trias de ce secteur, ainsi que des mentions du $\mathrm{XIX}^{\mathrm{e}}$ siècle (Bulliot 1888), ont orienté les recherches vers certaines carrières potentielles, en particulier autour de Saint-Emiland et de Taintry.

Méthodologie

6 La première étape a été l'établissement d'un inventaire des sarcophages en grès découverts autour des zones supposées de production dans le département de l'Allier, ainsi que dans les départements limitrophes tels que la Creuse, l'Indre, le Cher et la Nièvre, mais aussi en Bourgogne, en Île-de-France et en région Centre. Pour chaque lieu de découverte, et parfois après vérification sur place, une fiche type a été établie comportant toutes les informations disponibles sur le site (localisation, date et circonstance de la découverte, liste des interventions réalisées sur le site, inventaire des rapports et publications, nombre et lieu de conservation des sarcophages).

7 Dans un second temps, l'étude typologique sera entreprise pour les sites où il est possible d'avoir accès aux vestiges en question. Chaque sarcophage étudiable fera l'objet d'une fiche typomorphologique sur le modèle de celle établie pour les sites bourguignons (Henrion 2003), rassemblant des données technologiques et dimensionnelles. Le croisement de ces informations permet, en effet, d'extraire les caractères discriminants nécessaires à l'élaboration d'une classification et d'en dégager des groupes typologiques. L'établissement de ces groupes au sein du corpus étudié devrait ouvrir des nouvelles perspectives quant aux courants d'échanges et de circulations. Cet aspect sera surtout développé durant les exercices 2005-2006 du projet.

8 Le troisième aspect de cette étude, complémentaire du précédent, concerne les analyses pétrographiques des éléments funéraires. Celles-ci sont réalisées dans un premier temps à la loupe sur cassure fraîche, puis sur lame mince au microscope photonique. C'est, en effet, par la détermination des constituants minéraux et des composants biogènes éventuels qu'il est possible de définir la nature et l'âge de la roche dans laquelle les sarcophages ont été extraits. Outre l'intérêt typologique, cette approche permet de cerner des zones d'approvisionnement, voire d'identifier des lieux d'extraction. Parallèlement, une lithothèque de référence doit être élaborée à partir d'échantillons prélevés dans les carrières susceptibles d'avoir été exploitées anciennement. Cette démarche a été engagée dès la première année de ce PCR et se poursuivra jusqu'à son terme. 
Inventaire des sarcophages

Pour cette première année, les dépouillements bibliographiques ont porté sur 10 départements (Allier, Cher, Côte-d'Or, Creuse, Indre, Loire, Loiret, Nièvre, Saône-etLoire, Yonne) appartenant à cinq régions : l'Auvergne, la Bourgogne, le Centre, le Limousin et Rhône-Alpes. Ce travail, pour l'instant non exhaustif, concerne plus de 900 lieux de découverte de sarcophages, dont au moins 120 ayant livré des sarcophages en grès.

Ces investigations ont permis d'établir une première carte de répartition des sarcophages en grès dans les régions concernées.

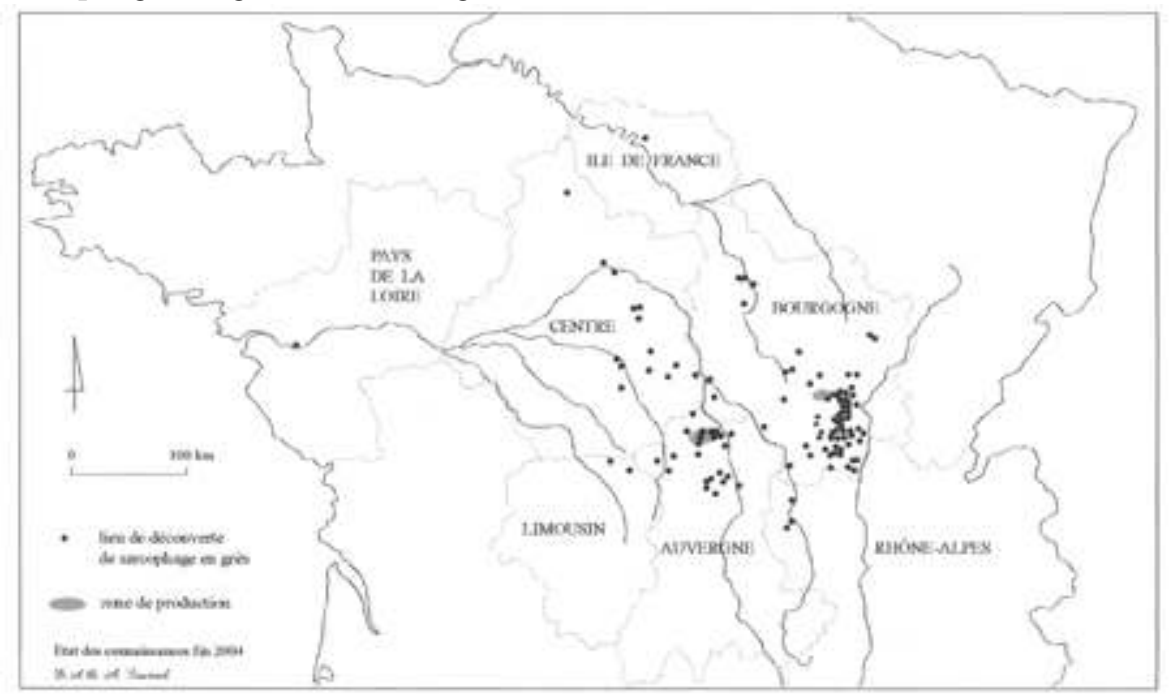

Carte de répartition des sarcophages en grès.

Analyses pétrographiques

10 Cette démarche a, pour l'instant, été engagée sur quelques échantillons prélevés sur des cuves et couvercles de sarcophages du sud et du centre de l'Allier, qu'ils aient été récemment mis au jour ou stockés depuis leurs découvertes anciennes. L'étude sur le sarcophage attribué aux saints Mayeul et Odilon - mis au jour par l'équipe de Pascale Chevalier dans l'église prieurale de Souvigny (Chevalier, Maquet 2003) - fait à ce titre office de référentiel (Henrion à paraître).

11 L'intégralité des sarcophages ayant fait l'objet d'une étude pétrographique est en grès permien du type de celui exploité dans le secteur de Coulandon. Il convient de noter que le site de Gannat présente un sarcophage en grès associé à un couvercle en calcaire lacustre oligocène local (type Chaptuzat). Cette constatation pourrait nous permettre d'envisager la limite méridionale de diffusion des sarcophages permiens suivant une ligne passant par Gannat et Vichy, sous réserve de nouvelles découvertes.

Perspectives et conclusions

12 Les inventaires établis mettent bel et bien en évidence deux principales concentrations de sarcophages en grès, la première environnant le secteur de production bourbonnais et l'autre se développant selon un axe grossièrement nord-sud entre Beaune (Côted'Or) et Cluny (Saône-et-Loire). La cartographie de ces découvertes confirme aussi la large diffusion des sarcophages en grès bien au-delà de ces deux zones de production. De fait, en 2005, les dépouillements devront être élargis à quelques autres départements - à savoir l'Ain, l'Eure-et-Loir, le Loir-et-Cher, le Puy-de-Dôme et le Rhône - afin de préciser les données sur les limites de la diffusion de ces sarcophages. 
De même, les études pétrographiques devront se multiplier plus particulièrement au nord de la zone de production bourbonnaise, afin d'évaluer la limite septentrionale effective de diffusion des sarcophages de ce type. Des investigations du même type sont programmées autour du district de production autunois, afin de caractériser au mieux les faciès effectivement exploités et l'aire de diffusion de cette production.

Par ailleurs, une attention particulière devra être portée aux secteurs situés entre les deux zones de concentration, afin d'essayer d'établir les limites des aires de diffusion respectives, voire de mettre en exergue les influences et les interpénétrations qui ont $\mathrm{pu}$ avoir lieu. Ce travail nécessitera la réalisation d'inventaires précis associés à la caractérisation typologique et pétrographique des sarcophages en question. Dans cette perspective, un effort portera sur la datation des sarcophages concernés, entreprise qui reste difficile pour les nombreux exemplaires dont le contexte précis de découverte est inconnu, mais qui pourra peut-être être facilitée par leur analyse typologique (technologie et morphologie).

Bibliographie

Archéologie en Languedoc, Nécropoles languedociennes de l'Antiquité tardive et du haut Moyen Âge, Revue de la fédération archéologique de l'Hérault, 4, 1987.

BERLAND, J. M. dom, "Le sarcophage mérovingien à croix multiples de Saint-Benoît-surLoire", Revue archéologique du centre de la France, 15-16, 1965, p. 295-308.

BuLliot, J. G., Les carrières et les carriers gallo-romains de Saint-Emiland, Mémoire de la Société Eduennes. Lettres, Sciences, Arts, n 16, 1888.

BÜTTNER, S., HENRION, F., "Les sarcophages du haut Moyen Âge en Bourgogne du nord: approches méthodologiques, premiers résultats et réflexions", Etudes et Travaux 2000-2001, Auxerre, Bulletin du Centre d'études médiévales, n 5, 2001, p. 24-37.

CHEVALIER, P., MAQUET, A., Des tombeaux, des reliques et des saints. Découverte des tombeaux et gisants des saints abbés de Cluny, Catalogue d'exposition, Souvigny, 2003.

CUVELIER, P., GUILlaume, J., "Inventaire et typologie des sarcophages en Lorraine", Préactes des $X^{e}$ journées d'archéologie mérovingienne, Metz, 1988. FAVIÈRE, J., "Les sarcophages antiques du Cher", Revue Archéologique de l'Est, VI, 1955, p. 40-54.

21 FIZELlieR-SAugET, B. (dir.), "L'Auvergne de Sidoine Apollinaire à Grégoire de Tours. Histoire et archéologie". Actes des XIII journées internationales d'archéologie mérovingienne, Clermont-Ferrand,1991, Clermont-Ferrand, Publication de l'institut d'études du Massif Central, fasc. 14, 1999 (p. 187-227 pour l'Allier). FOSSARD, D., "Répartition des sarcophages mérovingiens à décor en France", Études mérovingiennes, Actes des journées de Poitiers, 1952, Paris, 1953, p. 119-126. HENRION, F., "Le sarcophage de Souvigny et sa place dans les productions mérovingiennes", Actes de la table ronde La sculpture médiévale en région Auvergne, Clermont-Ferrand, 2003, à paraître. HENRION, F., "La morphologie des sarcophages du haut Moyen Âge comme critère typologique", Actes du colloque Archéologie des pratiques funéraires, approche critique, Glux-en-Glenne, 2001, à paraître. HENRION, F., Production et diffusion des sarcophages au haut Moyen Âge en Bourgogne du nord: état de la question, DEA “Archéologie des périodes historiques", Université Paris 1 Panthéon-Sorbonne, 2003. 

Archéologie d'un site monastique. 10 ans de recherche à l'abbaye Saint-Germain d'Auxerre, Auxerre, Centre d'études médiévales, Paris, CTHS, 2000, p. 340-363.

27 la table ronde La sculpture médiévale en région Auvergne, Clermont-Ferrand, 2003, à paraître.

\section{INDEX}

Mots-clés : sarcophage

Index géographique : France/Massif Central 